\author{
RESEARCH ARTICLE \\ 10.1029/2019JB017829 \\ Key Points: \\ - We make repeatable and reliable \\ estimates of the EED potential of \\ chalk, marl and shale using natural \\ water samples \\ - Chalk has a positive EED potential \\ and low exclusion efficiency. Marl \\ and shale have a negative EED \\ potential and high exclusion \\ efficiency \\ - SP modelling and monitoring in \\ heterogeneous environments \\ require rigorous characterisation of \\ the electrical properties of rock \\ samples
}

Supporting Information:

- Supporting Information S1

Correspondence to:

DJ. MacAllister,

donmac@bgs.ac.uk

Citation:

MacAllister, DJ., Graham, M. T.,

Vinogradov, J., Butler, A. P., \& Jackson, M. D. (2019). Characterizing the self-potential (SP) response to

concentration gradients in

heterogeneous subsurface

environments. Journal of Geophysical

Research: Solid Earth, 124, 7918-7933.

https://doi.org/10.1029/2019JB017829

Received 9 APR 2019

Accepted 6 JUL 2019

Accepted article online 10 JUL 2019

Published online 14 AUG 2019

(c)2019. American Geophysical Union. All Rights Reserved.

\section{Characterizing the Self-Potential Response to Concentration Gradients in Heterogeneous Subsurface Environments}

\author{
DJ. MacAllister 1,2,3 D, M. T. Graham ${ }^{1,2,4}$ (D) J. Vinogradov ${ }^{1,5}$ (D), A. P. Butler ${ }^{2}$ (D) and \\ M. D. Jackson ${ }^{1}$
}

${ }^{1}$ Department of Earth Science and Engineering, Imperial College London, London, UK, ${ }^{2}$ Department of Civil and Environmental Engineering, Imperial College London, London, UK, ${ }^{3}$ Now at British Geological Survey, The Lyell Centre, Edinburgh, UK, ${ }^{4}$ Now at WS Atkins Limited, Surrey, UK, ${ }^{5}$ Now at School of Engineering, King's College, University of Aberdeen, Aberdeen, UK

\begin{abstract}
Self-potential (SP) measurements can be used to characterize and monitor, in real-time, fluid movement and behavior in the subsurface. The electrochemical exclusion-diffusion (EED) potential, one component of SP, arises when concentration gradients exist in porous media. Such concentration gradients are of concern in coastal and contaminated aquifers and oil and gas reservoirs. It is essential that estimates of EED potential are made prior to conducting SP investigations in complex environments with heterogeneous geology and salinity contrasts, such as the UK Chalk coastal aquifer. Here we report repeatable laboratory estimates of the EED potential of chalk and marls using natural groundwater (GW), seawater (SW), deionized (DI) water, and $5 \mathrm{M} \mathrm{NaCl}$. In all cases, the EED potential of chalk was positive (using a GW/SW concentration gradient the EED potential was ca. 14 to $22 \mathrm{mV}$ ), with an increased deviation from the diffusion limit at the higher salinity contrast. Despite the relatively small pore size of chalk (ca. $1 \mu \mathrm{m}$ ), it is dominated by the diffusion potential and has a low exclusion efficiency, even at large salinity contrasts. Marl samples have a higher exclusion efficiency which is of sufficient magnitude to reverse the polarity of the EED potential (using a GW/SW concentration gradient the EED potential was ca. -7 to $-12 \mathrm{mV}$ ) with respect to the chalk samples. Despite the complexity of the natural samples used, the method produced repeatable results. We also show that first order estimates of the exclusion efficiency can be made using SP logs, supporting the parameterization of the model reported in Graham et al. (2018, https://doi.org/10.1029/2018WR022972), and that derived values for marls are consistent with the laboratory experiments, while values derived for hardgrounds based on field data indicate a similarly high exclusion efficiency. While this method shows promise in the absence of laboratory measurements, more rigorous estimates should be made where possible and can be conducted following the experimental methodology reported here.
\end{abstract}

\section{Introduction}

Real-time monitoring is becoming more important as the subsurface is increasingly used as a source of energy, a repository for waste and a source of freshwater supplies. In that context, self-potential (SP) monitoring has been shown to have a plethora of applications for fluid monitoring in subsurface environments. For example, SP monitoring has been applied to a variety of hydrological applications, including pumping tests (Jackson et al., 2012; Maineult et al., 2008; Rizzo et al., 2004), flow in a buried paleochannel (Revil et al., 2005), in a sinkhole (Jardani et al., 2006), subglacial flows (Kulessa, 2003), and monitoring of contaminant plumes (Arora et al., 2007; Naudet, 2003; Revil et al., 2009). SP can also be used to monitor enhanced oil and gas recovery (Gulamali et al., 2011; Jackson et al., 2012) and to characterize oil and gas reservoirs, including to better understand reservoir wettability (Alroudhan et al., 2015; Alroudhan et al., 2016; Jackson et al., 2016). It has also been applied to studies of $\mathrm{CO}_{2}$ sequestration (Vieira et al., 2012) and in geothermal applications (Darnet et al., 2004; Jardani et al., 2008; Revil et al., 1999).

Much of the focus for SP monitoring has been on the electrokinetic potential (EK), but the electrochemical exclusion-diffusion potential (EED) is also of interest where concentration gradients exist. For example, MacAllister et al. (2018) and Graham et al. (2018) demonstrate that borehole measurements of SP can 
provide spatial and temporal warning of an intruding saltwater-freshwater interface in coastal aquifers. Such concentration gradients also exist in oil reservoirs during water flooding for enhanced oil recovery (Gulamali et al., 2011; Jackson, Gulamali, et al., 2012) and in contaminated aquifers (Revil et al., 2009).

SP arises in order to maintain overall electrical neutrality when charge separation occurs due to gradients in pressure (EK) and concentration (EED; Revil, 1999). EED potentials remain poorly understood. Thus, the aim of this study was to develop a reliable and repeatable method for measuring the EED potential and assess how heterogeneities and variations in concentration gradient affect the EED potential. To our knowledge, no previous experiments of the EED potential have been conducted using natural water samples or natural chalk and marls. Several studies have reported EED potentials in sandstones (Hill \& Millburn, 1956; Leinov \& Jackson, 2014; Nourbehecht, 1963; Ortiz et al., 1973; Smits, 1968; Thomas, 1976), and one study estimated EED potential in argillite (Revil et al., 2005). Unlike sandstones, which were investigated by Leinov and Jackson (2014), carbonate rocks, such as chalk, react strongly with potential determining ions in pore waters via dissolution and adsorption processes (Al Mahrouqi et al., 2017; Alroudhan et al., 2016; Jackson et al., 2016). To investigate EED potentials in heterogeneous carbonate environments, we obtained natural chalk, marl, and water samples from a chalk coastal aquifer near Brighton on the South Coast of the UK, which is known to be affected by seawater intrusion. The objectives of the study were as follows: (i) make repeatable estimates, for the first time, of the EED potential component of SP in chalk using natural groundwater and seawater samples by modifying and extending the method developed by Leinov and Jackson (2014), (ii) investigate how two different concentration gradients affect the magnitude of the EED potential in chalk, and (iii) assess the role of different chalk lithologies, including marls and hardground, on the magnitude of the EED potential.

\section{Materials and Methods}

Three different sets of experiments were conducted; the first used natural groundwater and seawater and are referred to as the GW/SW experiments. The second set of experiments used deionized (DI) water and $5 \mathrm{M}$ $\mathrm{NaCl}$, both of which were allowed to equilibrate with chalk fragments (following the method outlined in Alroudhan et al., 2016) for several weeks prior to the experiments and which represented an end-member of a large concentration contrast and simple ionic composition. These experiments are referred to as the $\mathrm{DI} / 5 \mathrm{M}$ experiments. The third set of experiments used the GW/SW concentration gradient but used chalk marl samples to investigate the influence of natural heterogeneities in the chalk aquifer. These experiments are referred to as the heterogeneity experiments. As a benchmark, a shale core was also tested to ensure that the experiments produced reliable results and that a negative potential, suggesting a dominance of the exclusion potential, could be measured. Shale was used because it has a microporous matrix and should be dominated by the exclusion potential. All experiments were conducted in the Novel Reservoir Modelling and Simulation Laboratory at Imperial College London, with a controlled temperature of $22.5 \pm 1{ }^{\circ} \mathrm{C}$.

The EED potential, which cannot be directly measured, was estimated by measuring the potential difference across rock samples placed between a low and high salinity reservoir, which created a concentration gradient across the sample. The experiments were designed such that no other SP source mechanisms (e.g., pressure gradients which generate electrokinetic potentials) were present. The rock sample was initially saturated with the low salinity electrolyte, for two reasons; the first was that this mimics seawater intrusion; the second was that the electrical double layer (EDL), a layer of counter-ions adjacent to the rock surface within the pore space, is thickest when the saturating electrolyte is of low salinity (Revil \& Pezard, 1999), meaning that co-ions are more likely to be excluded from within the pore space and an exclusion dominated EED potential observed.

A two-stage approach was taken to account explicitly for electrode effects (Jougnot \& Linde, 2013; Leinov \& Jackson, 2014). The "column" apparatus (Figure 1b) facilitated estimates of the electrochemical diffusion potential across the salinity front without the porous media. The "plug" experiment (Figure 1a) facilitated estimates of the EED potential across the rock samples. Note that in contrast to the thin samples used by Leinov et al. (2010) and Leinov and Jackson (2014), the rock plugs used were a minimum length of ca. $50 \mathrm{~mm}$ in order to avoid leakage around the samples. Furthermore, the longer samples made it easier to achieve a stable initial voltage measurement. The total electric potential measured in the plug experiment 
(a) Thermocouple

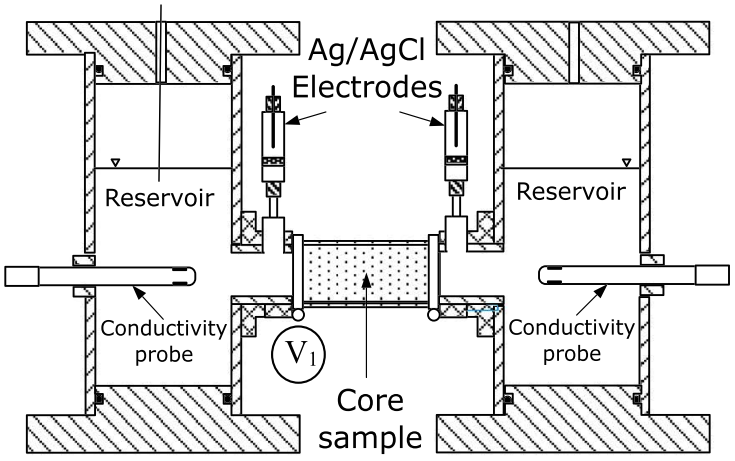

(c)

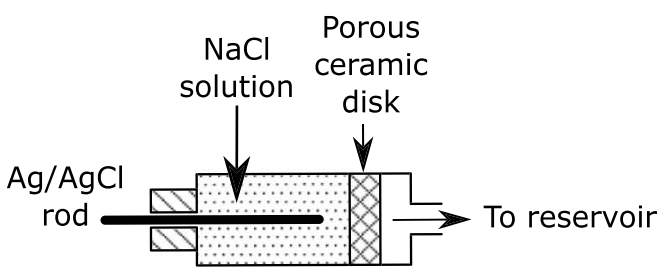

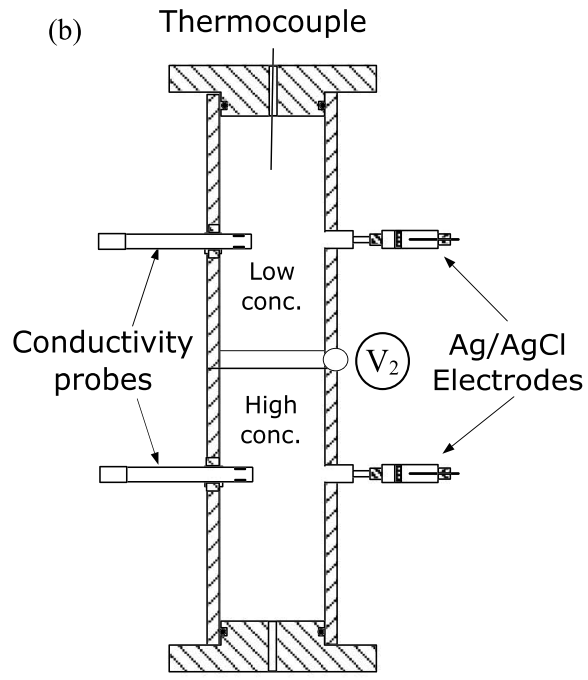

Figure 1. (a) Configuration of the "plug" experiment for measuring the electrochemical exclusion-diffusion potential across a salinity front in rock samples. (b) Configuration of the "column" experiment for isolating the diffusion potential and measuring electrode effects. (c) Detail of the electrode design.

(Figure 1a) is termed the apparent plug electric potential $\left(\Delta V_{A P}\right)$. It is made up of the EED potential $\left(\Delta V_{E E D}\right)$ and a concentration dependent electrode potential ( $\Delta V_{C}$; Leinov et al., 2010, Leinov \& Jackson, 2014):

$$
\Delta V_{A P}=\Delta V_{E E D}+\Delta V_{C}
$$

The electrode potential was removed by conducting a second experiment using refreshed but, otherwise identical, electrodes without the chalk plug. Instead, the two reservoirs (Figure 1b) were connected in a vertical column arrangement and the electric potential across the gravity-stabilized salinity front was measured. The apparent column electric potential $\left(\Delta V_{A C}\right)$ was made up of the diffusion potential $\left(\Delta V_{E D}\right)$ and a concentration-dependent electrode effect $\left(\Delta V_{C}\right)$, which was assumed to be identical to the electrode effect in the plug experiment (Leinov et al., 2010; Leinov \& Jackson, 2014):

$$
\Delta V_{A C}=\Delta V_{E D}+\Delta V_{C}
$$

In these experiments, the electrolytes used are natural and as such contain multiple ionic species. The diffusion potential for multi-ionic electrolytes was calculated using the expression developed by Lanteri et al. (2009):

$$
\Delta V_{E D}=-\frac{k_{B} T}{e}\left(\frac{\sum_{i} K_{i} D_{i} z_{i}\left(C_{M i}^{\Delta x}-C_{i}^{0}\right)}{\sum_{i} K_{i} D_{i} z_{i}^{2}\left(C_{M i}^{\Delta x}-C_{i}^{0}\right)}\right) \ln \left(\frac{\sum_{i} K_{i} D_{i} z_{i}^{2} C_{M i}^{0}}{\sum_{i} K_{i} D_{i} z_{i}^{2} C_{M i}^{\Delta x}}\right)
$$

Here $k_{B}$ is the Boltzmann constant, $T$ is the absolute temperature, $e$ is the electron charge, $K_{i}$ is the hindrance diffusion coefficient, which for the case of an infinite pore volume is $1, D_{i}$ is the diffusion coefficient (following Lanteri et al., 2009), values of which are taken from Haynes and Lide (2012) for each ion, $z_{i}$ is the charge number of ion $i, C_{M i}^{0}$ is the concentration of each ion the highest salinity solution and $C_{M i}^{\Delta x}$ is the concentration of each ion the lowest salinity solution. Equation (3) is equivalent to the expression used by Leinov and Jackson (2014) in the case of a 1:1 electrolyte (see supporting information (SI) Text S1).

Combining equations (1) and (2) gives an expression for the EED potential:

$$
\Delta V_{E E D}=\Delta V_{A P}-\left(\Delta V_{A C}-\Delta V_{E D}\right)
$$

Voltage measurements were made using an NI-9219 voltmeter with an internal impedance $>1 \mathrm{G} \Omega$, an accuracy of $0.18 \%$ of the full-scale measurement $(1 \mathrm{~V})$ and resolution of $50 \mathrm{nV}$. The electrical conductivity of the 
electrolytes was measured using Jenway 4520 conductivity meters $( \pm 0.5 \%$ accuracy and resolution of 0.01 $\mu \mathrm{S} / \mathrm{cm}$ ), and the temperature was measured using K-type isolated thermocouples (accuracy $\pm 0.5{ }^{\circ} \mathrm{C}$ ). Voltage, temperature, and electrical conductivity were recorded with a 1-Hz sampling frequency.

\subsection{Electrodes}

Leinov and Jackson (2014) found that electrode effects dominated the estimated EED potential and so developed their method with the expressed intent of accounting explicitly for these effects. Here we also account for electrode effects, but the method used differs from that of Leinov and Jackson (2014). They used uncased $\mathrm{Ag} / \mathrm{AgCl}$ electrodes placed directly into the main reservoirs, which were filled with $\mathrm{NaCl}$ solution. In the experiments reported here the range of ionic species present in the natural waters, used to fill the main reservoirs, were highly reactive with the bare electrode surface and caused problems with electrode stability and experimental repeatability. To minimize these effects, the electrodes were placed in a smaller $\mathrm{NaCl}$ filled reservoir and separated from the main reservoir using a low-permeability ceramic disk (Figure 1c).

The use of a NaCl-filled electrode casing results in a liquid junction potential between the main reservoir and the electrode casings (Barry \& Diamond, 1970; Jougnot \& Linde, 2013), because of differences in ionic species and concentrations between them. However, the presence of chloride ions in the electrode casing slows dissolution of the silver chloride coating on the silver electrode rod (Raynauld \& Laviolette, 1987), which avoids the creation of time-dependent and irreversible equilibrium contact potentials (Jougnot \& Linde, 2013). The chloride ions in the casings also control the intrinsic potential of the electrode (Jougnot \& Linde, 2013; Junge, 1990). The presence of the ceramic disk ensured reduced noise and increased electrode stability by slowing the migration of other ionic species into the electrode casings, preventing unwanted contact potentials (Snyder et al., 1999), minimized convective mixing and helped ensure that the chloride content was kept as stable as possible for the duration of the experiment. The reproducibility of electrode potentials was tested by repeating the column experiment fifteen times for the GW/SW experiments and 6 times for the DI/5M experiments (for further details see SI Text S5).

To prepare the $\mathrm{NaCl}$ solutions used in the electrode casings, the electrical conductivity of the main reservoir fluids was measured (in S/m) and then converted to concentration using the expression (equation (5)) developed by Vinogradov et al. (2010). The resulting $\mathrm{NaCl}$ solutions had a higher chloride content than the chloride content in the main reservoirs (ca. 5 times higher in the low salinity electrode casing and ca. 1.25 times higher in the seawater casing). The higher chloride content in the electrode casings, relative to the main reservoirs, buffered the effect of ionic concentration gradients across the ceramic disk (Tallgren et al., 2005) and ensured that the chloride concentration in the electrode casings remained reasonably constant throughout the duration of each experiment.

$$
\begin{aligned}
C_{M}= & 5.9738 \times 10^{-7} \sigma_{f e c}{ }^{6}-3.5136 \times 10^{-5} \sigma_{f e c}{ }^{5}+7.823 \times 10^{-4} \sigma_{f e c}{ }^{4}-8.0334 \times 10^{-3} \sigma_{f e c}{ }^{3} \\
& +4.0791 \times 10^{-2} \sigma_{f e c}{ }^{2}+3.4996 \times 10^{-2} \sigma_{f e c}+3.6104 \times 10^{-2}
\end{aligned}
$$

It is impossible to eliminate completely diffusion across the ceramic disk and all of the ionic species within the natural electrolytes in the main reservoirs will diffuse into the electrode casing over time. Despite this, the electrode design ensured that the electrodes were stable for the first hour of the experiments and that the measurements were repeatable. Once the electrodes started to drift, the experiments were terminated. At the start of each experiment, a new set of electrodes was prepared for both the column and plug apparatus.

\subsection{Measurements Procedure}

In the column experiment, the lower reservoir was filled with the high-salinity electrolyte (Figure $1 \mathrm{~b}$ ). The two reservoirs were separated by a ball valve $\left(\mathrm{V}_{2}\right.$ in Figure $\left.1 \mathrm{~b}\right)$ with the same diameter as the column. The lower reservoir was filled just above the ball valve to ensure that no air was trapped and then the valve was closed. Any excess water was cleared from the compartment separating the two reservoirs, and the upper reservoir was filled with the low-salinity electrolyte. Since the denser water was at the base of the column, no convective mixing occurred and the salinity front was stable once the ball valve was opened, at which point the experiment started. 
In the plug experiments (Figure 1a), the rock sample, initially saturated with the low-salinity electrolyte, was placed in a rubber sleeve and attached to the low salinity reservoir, which was then filled. The core sample was wrapped in PTFE tape, a type of deformable filler, which was used to seal the contact between the core and the rubber sleeve. The high-salinity reservoir was then filled; a valve at the end of the core channel ensured that the reservoir did not leak. The water level in each reservoir was identical, so no pressure gradients existed across the sample. Once the electrodes were attached, the measurements started. Then the valve $\left(\mathrm{V}_{1}\right.$ Figure $\left.1 \mathrm{a}\right)$ at the end of the core channel was opened. At this point, the electrical contact between the two reservoirs was established and the experiment began. All measurements were taken with reference to the electrode in the low salinity reservoir.

The water samples used in the reservoirs were analyzed for the ionic concentrations of their constituent components once experimental repeatability was achieved. Aliquots were sampled from random experiments to ensure that there was no significant change in the ionic concentrations of the electrolytes that were used (i.e., in the case of groundwater and preequilibrated DI water $<20 \%$ for major ionic constituents and in all samples $<50 \%$ for minor ionic constituents; these values were determined based on a basic sensitivity analysis of equation (3)).

In the GW/SW experiments, the chalk samples were presaturated with groundwater. The average ionic concentration for groundwater and seawater are shown in SI Text S2; these values were used in equation (1) (Lanteri et al., 2009) to calculate the diffusion potential. The seawater electrodes internal electrolyte was created from $55 \mathrm{mS} / \mathrm{cm} \mathrm{NaCl}$ solution in deionized water (the conductivity of the deionized water was $<1$ $\mu \mathrm{S} / \mathrm{cm}$ ). The chloride content of these electrodes was ca. $24,160 \mathrm{mg} / \mathrm{L}$. The groundwater electrodes internal electrolyte was created using the same starting electrolyte as the seawater electrode, but the solution was diluted by 100 times, giving an electrode with an internal conductivity of ca. $675 \mu \mathrm{S} / \mathrm{cm}$. The chloride content of these electrodes was ca. $241 \mathrm{mg} / \mathrm{L}$.

In the DI/5M experiments, the high salinity electrode had an internal $5 \mathrm{M} \mathrm{NaCl}$ solution. The low salinity electrode was identical to the electrode used in the GW/SW experiments, because the use of deionized water resulted in electrode instability. The rest of the experimental procedure was the same as described for the $\mathrm{GW} / \mathrm{SW}$ experiments.

\subsection{Sample Characterization}

Natural groundwater samples were taken from the Chalk aquifer in East Sussex and seawater samples were taken from the English Channel. Prior to being used in the experiments the groundwater and seawater were filtered using 0.6-mm filter paper and exposed to UV radiation, to remove suspended matter and bacteria or other microorganisms present in the samples. After UV treatment the samples were filtered once more before being used in the experiments.

Sample aliquots were taken from the main reservoirs (Figure 1) before beginning each experiment and were stored at $4{ }^{\circ} \mathrm{C}$ prior to analytical analysis, which was used to determine the ionic concentrations of constituent ions of each electrolyte used in the experiments. All aliquots were analyzed using ion chromatography (Eith et al., 2001; Jackson, 2000), titration for carbonate and bicarbonate analysis (Franson, 1998), and inductively coupled plasma atomic emission spectroscopy (Tatro \& Amarasiriwardena, 2006) for silica, strontium, and barium. The average ionic composition of the groundwater and seawater are shown in SI Text S2. Note that samples were only used in the calculation for the EED potential if they had a charge balance error less than 5\% (Hounslow, 1995).

In the DI/5M experiments, the low-salinity electrolyte was prepared using deionized water preequilibrated with chalk following the procedure described by Alroudhan et al. (2016). Similarly, the high-salinity electrolyte used $5 \mathrm{M}$ solutions of $\mathrm{NaCl}$. The average analysis of the low salinity electrolyte and the $5 \mathrm{M}$ electrolyte are shown in SI Text S3. Samples were only used in the calculation for the EED potential if they had a charge balance error $<10 \%$.

Four different chalk samples were used in the experiments; two marl samples and a shale sample were also tested. Details of these samples are shown in Table 1 including measurements of pore throat radii which were made using mercury injection for each of the chalk samples. Zeta potentials, an indicator of mineral surface charge, were also measured in the laboratory for the chalk samples following the method described in Vinogradov et al. (2010). The values of zeta potential and pore throat radius for marl and shale samples are 
Table 1

Details of Rock Samples Used in the Experiments

\begin{tabular}{|c|c|c|c|c|c|c|c|}
\hline \# & Chalk type & Source & Length (mm) & Diameter (mm) & Porosity & Permeability (mD) & $\begin{array}{l}\text { Pore-throat } \\
\text { radius (nm) }\end{array}$ \\
\hline $\mathrm{C} 1$ & Seaford & Berkshire & $52.5 \pm 0.05$ & $37.4 \pm 0.05$ & 0.46 & $2.5 \pm 0.10$ & 950.6 \\
\hline $\mathrm{C} 2$ & Seaford & Worthing & $69.3 \pm 0.05$ & $36.8 \pm 0.05$ & 0.38 & $2.1 \pm 0.11$ & 817.6 \\
\hline $\mathrm{C} 3$ & Seaford & London & $77.1 \pm 0.05$ & $37.8 \pm 0.05$ & 0.37 & $\sim 2.0^{\mathrm{a}}$ & 654.1 \\
\hline $\mathrm{C} 4$ & Lewes & Kent & $76.1 \pm 0.05$ & $37.7 \pm 0.05$ & 0.41 & $\sim 2.0^{\mathrm{a}}$ & $1,332.8$ \\
\hline M1 & Seaford & Berkshire & $51.0 \pm 0.05$ & $37.0 \pm 0.05$ & $\sim 0.30^{\mathrm{b}}$ & $\sim 0.8^{\mathrm{b}}$ & $\sim 100^{\mathrm{b}}$ \\
\hline M2 & Lewes & Kent & $40.0 \pm 0.05$ & $37.0 \pm 0.05$ & $\sim 0.30^{\mathrm{b}}$ & $\sim 0.8^{\mathrm{b}}$ & $\sim 100^{\mathrm{b}}$ \\
\hline S1 & Shale & Black shale & $10.0 \pm 0.05$ & $37.0 \pm 0.05$ & $\sim 0.06^{\mathrm{c}}$ & $\sim 0.003^{\mathrm{c}}$ & $\sim 20^{\mathrm{c}}$ \\
\hline \# & Chalk type & Source & SW conductivity $(\mathrm{mS} / \mathrm{cm})$ & $\mathrm{GW}$ conductivity $(\mathrm{mS} / \mathrm{cm})$ & Formation factor & Cementation exponent $\mathrm{m}$ & $\begin{array}{c}\text { Zeta-potential } \\
(\mathrm{mV})\end{array}$ \\
\hline $\mathrm{C} 1$ & Seaford & Berkshire & $6.69 \pm 0.011$ & $0.331 \pm 0.0002$ & $7.31 \pm 0.11$ & $2.58 \pm 0.01$ & $-20.1 \pm 3.21$ \\
\hline C2 & Seaford & Worthing & $5.05 \pm 0.082$ & $0.245 \pm 0.0014$ & $9.97 \pm 1.73$ & $2.36 \pm 0.16$ & $-20.3 \pm 3.12$ \\
\hline C3 & Seaford & London & $6.16 \pm 0.025$ & $0.301 \pm 0.0010$ & $8.17 \pm 0.32$ & $2.12 \pm 0.04$ & $\sim-10--20^{\mathrm{d}}$ \\
\hline $\mathrm{C} 4$ & Lewes & Kent & $5.20 \pm 0.004$ & $0.250 \pm 0.0004$ & $9.68 \pm 0.07$ & $2.56 \pm 0.01$ & $\sim-10-20^{\mathrm{d}}$ \\
\hline M1 & Seaford & Berkshire & $4.52 \pm 0.003$ & $0.488 \pm 0.0003$ & $\mathrm{~N} / \mathrm{A}$ & $\mathrm{N} / \mathrm{A}$ & $\sim-20--80^{\mathrm{e}}$ \\
\hline M2 & Lewes & Kent & $4.95 \pm 0.004$ & $0.493 \pm 0.0004$ & $\mathrm{~N} / \mathrm{A}$ & $\mathrm{N} / \mathrm{A}$ & $\sim-20--80^{\mathrm{e}}$ \\
\hline S1 & Shale & Black shale & $\mathrm{N} / \mathrm{A}$ & N/A & N/A & N/A & $\sim-30--40^{\mathrm{f}}$ \\
\hline
\end{tabular}

Note. Some parameters were not directly measured in the laboratory. Mean values for pore-throat radius are taken from

${ }^{a}$ Bloomfield et al. (1995) for chalk ${ }^{b}$ Fay-Gomord et al. (2016) for marl, and ${ }^{c}$ Nelson (2009) for shale. Ranges for zeta potential are based on ${ }^{d}$ Jackson, Butler, et al. (2012) and our own laboratory measurements for chalk. Marl zeta potentials are based on ${ }^{\mathrm{e}} \mathrm{Mammar}$ et al. (2001) who used a range of NaCl solutions, including solutions with similar concentrations to groundwater, and Jackson et al. (2012). The ranges of zeta potential for marl represent end members of mostly pure chalk and pure clay. Finally, zeta potential for the shale sample is based on ${ }^{\mathrm{f}}$ Barati et al. (2017) who made measurements using distilled water.

taken from the literature. Prior to each experiment, the samples were cleaned following standard core cleaning procedures (Byrne \& Patey, 2004) using a Soxhlet extractor and methanol.

\subsection{Measurement Errors}

Conservative error estimates were made for each stage of the experimental process. The error in the diffusion potential $\left(\in_{V_{E D}}\right)$ was based on the range of concentration values available from repeat analysis of the water samples (SI Texts S2 and S3). Minimum and maximum diffusion potential estimates (using equation (3)) were calculated using the minimum and maximum concentration gradients possible in the experiments. The range of concentration gradients was based on the ionic concentration error values shown in SI Texts S2 and S3. The maximum deviation from the median calculated diffusion potential was taken as the diffusion potential error. The error in the apparent column $\left(\in_{V_{A C}}\right)$ and plug $\left(\in_{V_{A P}}\right)$ voltage were determined from repeat measurements using the maximum deviation from the mean as the error for the apparent column and plug potential measurements (see SI Text S5). The final error $\left(\in_{V_{E E D}}\right)$ in the EED potential was determined using equation (6) and the error in the electrode potential was calculated using equation (7):

$$
\begin{aligned}
& \epsilon_{V_{E E D}}=\epsilon_{V_{E D}}+\epsilon_{V_{A P}}+\epsilon_{V_{A C}} \\
& \epsilon_{V_{C}}=\epsilon_{V_{E D}}+\epsilon_{V_{A C}}+\epsilon_{V_{A C}}
\end{aligned}
$$

\section{Results}

A summary of the results from the column experiment are shown in Table $2 \mathrm{a}$ and from the plug experiments in Table 2b. Each of the repeat measurements for all experiments are shown in SI Text S5. Despite the complexity of the natural water samples, the electrode design ensured the experiments were repeatable. The electrode design used also ensured that voltage measurements were stable (Figures 2 and 3) which in turn helped decrease the overall error associated with the experimental method by reducing measurement error and slowing drift of the electrodes. Despite effective electrode design, electrode effects (Table 2a) dominated the measured voltages, for the GW/SW experiment the electrode potential was $-108.82 \pm 7.4 \mathrm{mV}$ and for the $\mathrm{DI} / 5 \mathrm{M}$ experiments the electrode potential was $-172.53 \pm 5.7 \mathrm{mV}$. 
Table 2

(a) Summary of the "Column" Experimental Results and (b) Summary of the "Plug" Experimental Results

\begin{tabular}{|c|c|c|c|c|}
\hline \multicolumn{2}{|l|}{ (a) } & $\begin{array}{c}\text { Average column } \\
\text { voltage } \Delta V_{A C}(\mathrm{mV})\end{array}$ & $\begin{array}{l}\text { Diffusion potential } \\
\qquad \Delta V_{E D}(\mathrm{mV})\end{array}$ & $\begin{array}{c}\text { Electrode potential } \\
\Delta V_{C}(\mathrm{mV})\end{array}$ \\
\hline \multicolumn{2}{|c|}{ GW/SW Experiment } & $-80.93 \pm 2.6$ & $27.89 \pm 4.8$ & $-108.82 \pm 7.4$ \\
\hline \multicolumn{2}{|c|}{ DI/5M Experiment } & $-128.22 \pm 1.1$ & $44.30 \pm 4.6$ & $-172.53 \pm 5.7$ \\
\hline \multirow[t]{8}{*}{ (b) } & Chalk sample & $\begin{array}{c}\text { Average plug voltage } \\
\qquad V_{A P}(\mathrm{mV})\end{array}$ & $\begin{array}{c}\mathrm{GW} / \mathrm{SW} \\
\Delta V_{E E D}(\mathrm{mV})\end{array}$ & $5 \mathrm{M} / \mathrm{DI} \Delta V_{E E D}(\mathrm{mV})$ \\
\hline & $\mathrm{C} 1$ & $-86.60 \pm 0.56$ & $22.22 \pm 7.91$ & N/A \\
\hline & $\mathrm{C} 2$ & $-94.21 \pm 1.20$ & $14.61 \pm 8.55$ & $18.24 \pm 7.68$ \\
\hline & $\mathrm{C} 3$ & $-87.44 \pm 2.46$ & $21.38 \pm 9.81$ & $32.19 \pm 5.77$ \\
\hline & $\mathrm{C} 4$ & $-86.23 \pm 1.27$ & $22.60 \pm 8.62$ & $31.82 \pm 7.37$ \\
\hline & M1 & $-116.68 \pm 3.22$ & $-7.71 \pm 10.8$ & N/A \\
\hline & M2 & $-121.64 \pm 3.11$ & $-12.19 \pm 9.9$ & N/A \\
\hline & $\mathrm{S} 1$ & $\mathrm{~N} / \mathrm{A}$ & $\mathrm{N} / \mathrm{A}$ & $-14.21 \pm 5.74$ \\
\hline
\end{tabular}

Note. All of the repeat experimental results of the column and plug experiments can be found in SI Text S5.

Typical results from the column experiments using GW/SW are shown in Figure 2. The voltage drifted initially but then the electrodes stabilized to within $\pm 50 \mu \mathrm{V}$. After a period of $2 \mathrm{hr}$, the voltage drifted again. The reason for the voltage drift is not clear but may be due to diffusion of ionic species from the natural groundwater and seawater samples across the ceramic disk into the electrode casings (Figure 1c). The conductivity in both reservoirs remained constant throughout this period. The stabilized voltage, averaged across a period of ca. $1.5 \mathrm{hr}$ after the initial drift, was taken as the apparent column voltage $\left(\Delta V_{A C}\right.$, equation (3)). The stabilized voltage was used to calculate the electrode potential. The column experiment was repeated 15 times for the GW/SW experiments. For the DI/5M experiments it was repeated 6 times.

Typical experimental result from the plug experiments are shown in Figure 3. Where possible a minimum of three repeat experiments were conducted for each rock sample, for both the GW/SW and the DI/5M experiments. Measurements of the voltage averaged across a period of ca. $1 \mathrm{hr}$ were taken as the apparent plug voltage $\left(\Delta V_{A P}\right.$, equation (4)). After $1 \mathrm{hr}$ significant drift of the voltage occurred and the experiment was terminated. The average value from the repeat plug experiments were used to calculate the EED potentials, using equation (4), for each rock sample (Table $2 \mathrm{~b}$ ). Similar behavior was observed in the DI/5M experiments, so these results are not reproduced here.

Figure 4 shows the results of EED potential estimates after removing electrode effects. The results are expressed as a function of concentration ratio, calculated as the ratio of the total ionic strength of the high and low salinity electrolytes shown in SI Texts S2 and S3.

At the $\mathrm{GW} / \mathrm{SW}$ concentration ratio and in chalk, the maximum EED potential was $+22.60 \pm 8.62 \mathrm{mV}$, and the smallest was $+14.61 \pm 8.90 \mathrm{mV}$. For the DI/5M experiments using chalk, the maximum EED potential was $+32.19 \pm 5.77 \mathrm{mV}$ and the minimum was $+17.45 \pm 7.68 \mathrm{mV}$. In the $\mathrm{DI} / 5 \mathrm{M}$ experiments, the values were further from the diffusion limit. For all chalk samples, the EED potential was positive. The marl core samples both showed a negative EED potential using GW/SW, with a maximum value of $-7.91 \pm 9.0 \mathrm{mV}$ and a minimum of $-12.19 \pm 8.3 \mathrm{mV}$. The shale sample had the most negative EED potential with the $5 \mathrm{M} / \mathrm{DI}$ concentration gradient and were $-14.21 \pm 5.74 \mathrm{mV}$.

\section{Discussion}

The methodology developed for measuring the EED potential using natural water and rock samples successfully produced stable, repeatable, and reliable experimental results. Key to the adapted method was electrode design; in particular, it was essential to maintain higher chloride concentrations in the electrodes than in the natural water samples contained in the corresponding reservoirs. Other electrode designs were tested but none were able to provide the level of repeatability or stability shown in Figures 2 and 3. In fact, no other design was able to reproduce a consistent electrode potential, which was crucial to the experimental method reported. Thus, when conducting measurements of the EED potential using natural water samples, we highly recommend following the electrode preparation procedure outlined in section 2.1. Despite the 
(a)

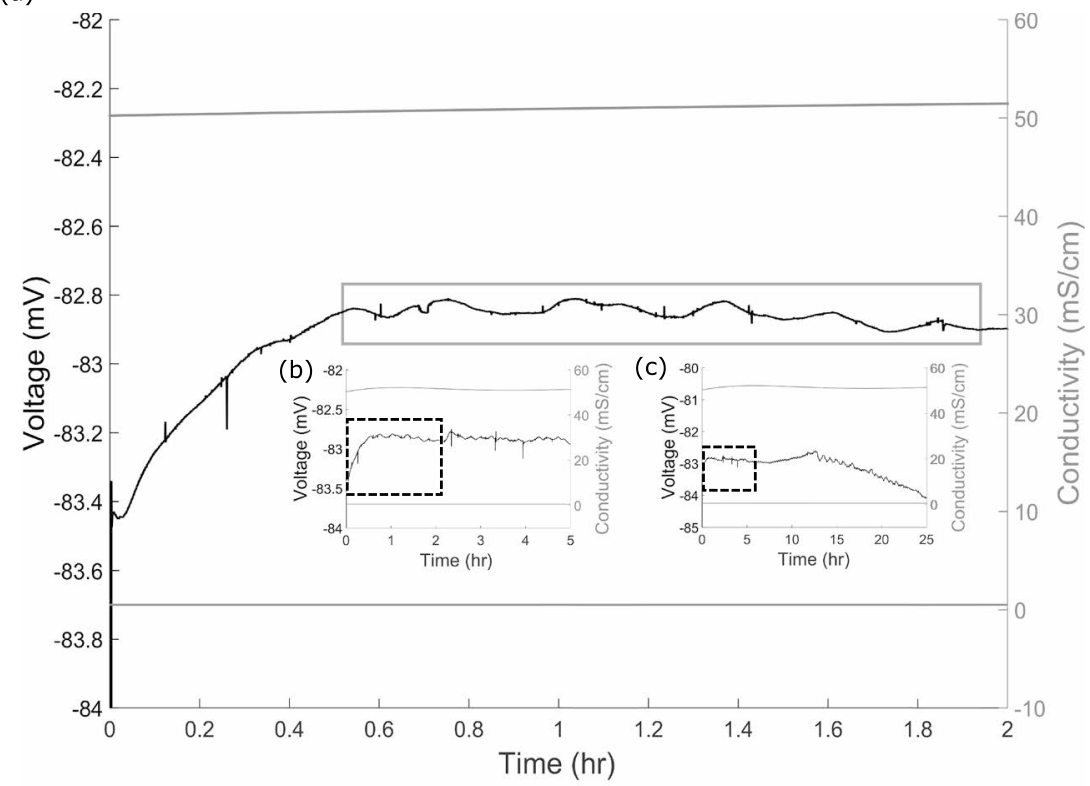

(d)

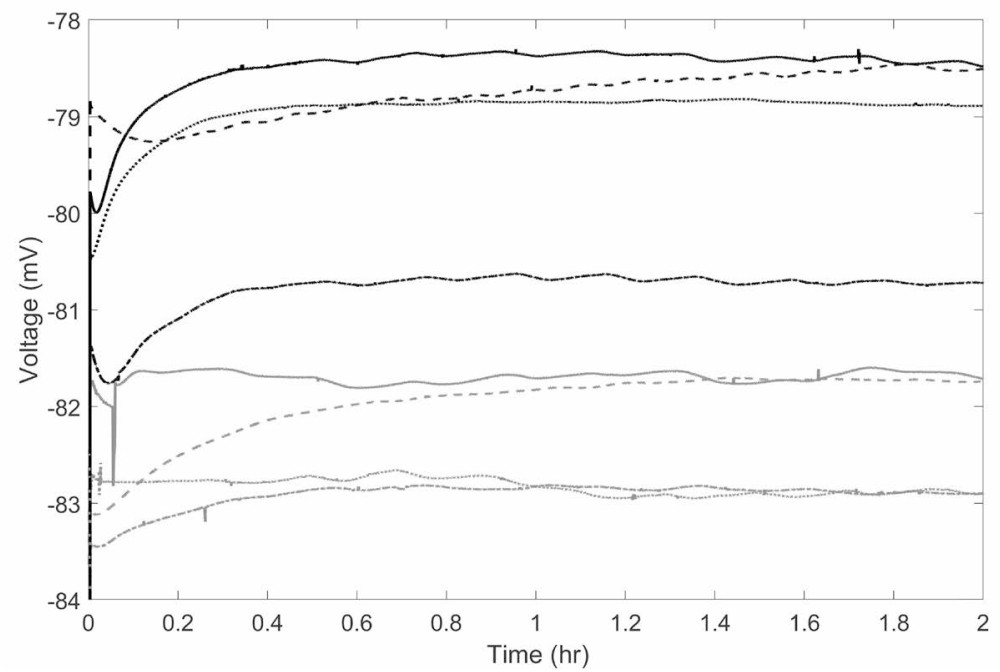

Figure 2. (a) Typical result for the "column" experiment using groundwater/seawater. The main figure shows the results for the first $2 \mathrm{hr}$ of the experiment, the grey box illustrates the area from which the apparent column voltage was taken. (b) The results for the first $5 \mathrm{hr}$ and the area (dashed box) from which the results in (a) are taken. (c) Shows the results for $25 \mathrm{hr}$ illustrating that after the first hour of the experiment significant drift of the voltage occurred. Also shown is the area from which the results in (b) are taken (dashed box). (d) Selected additional results from the column experiments illustrating the repeatability and stability of the method.

reliability of the electrodes, our results show that the electrode potential dominates the measured voltage in all experiments (Table 2a) and must always be accounted for. However, it is clear from our results that it is possible to make reliable and repeatable estimates of the EED potential in complex natural water samples if the electrodes are designed appropriately.

The EED potential in pure chalk samples was positive (with respect to a reference electrode in the low salinity reservoir) for both the GW/SW and DI/5M experiments (Figure 4). There was a small exclusion component at both salinity contrasts, although deviation from the diffusion limit (indicated by the black line in Figure 4) was greater in the DI/5M experiment. Figure 4 also shows that clay minerals, which are present in the marl and shale samples, can profoundly affect estimated values of the EED potential. Clean sandstone and chalk samples produce consistently positive values of the EED potential, indicating a dominance of 
(a)

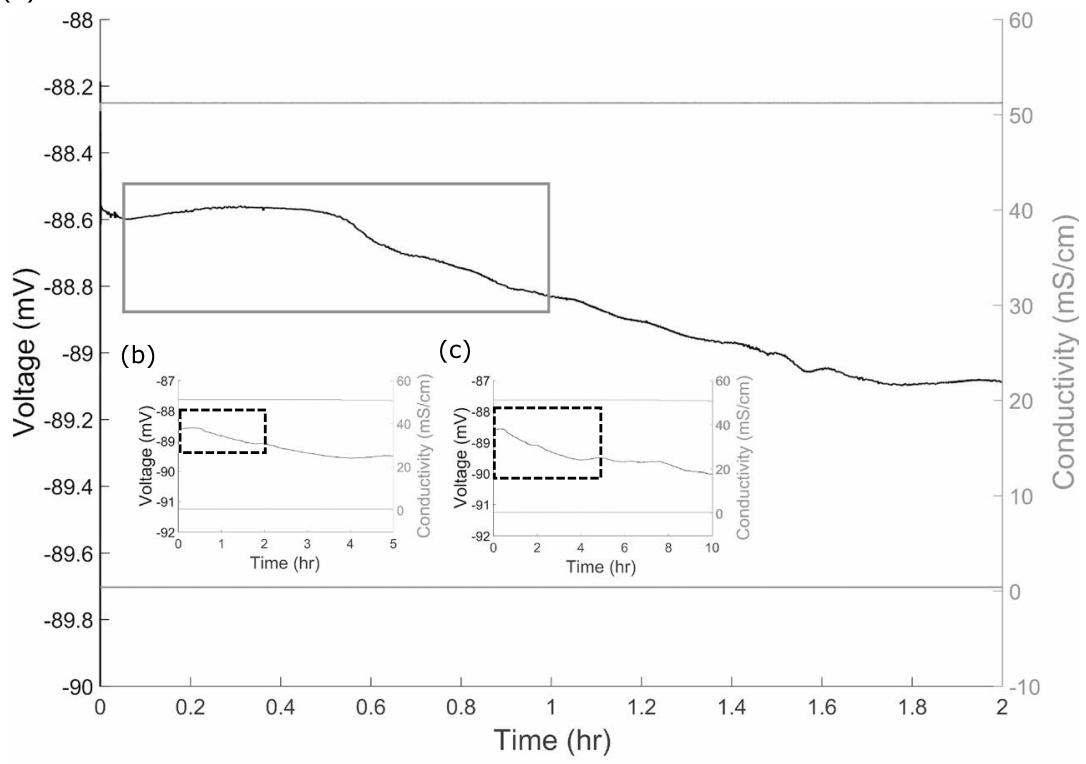

(d)

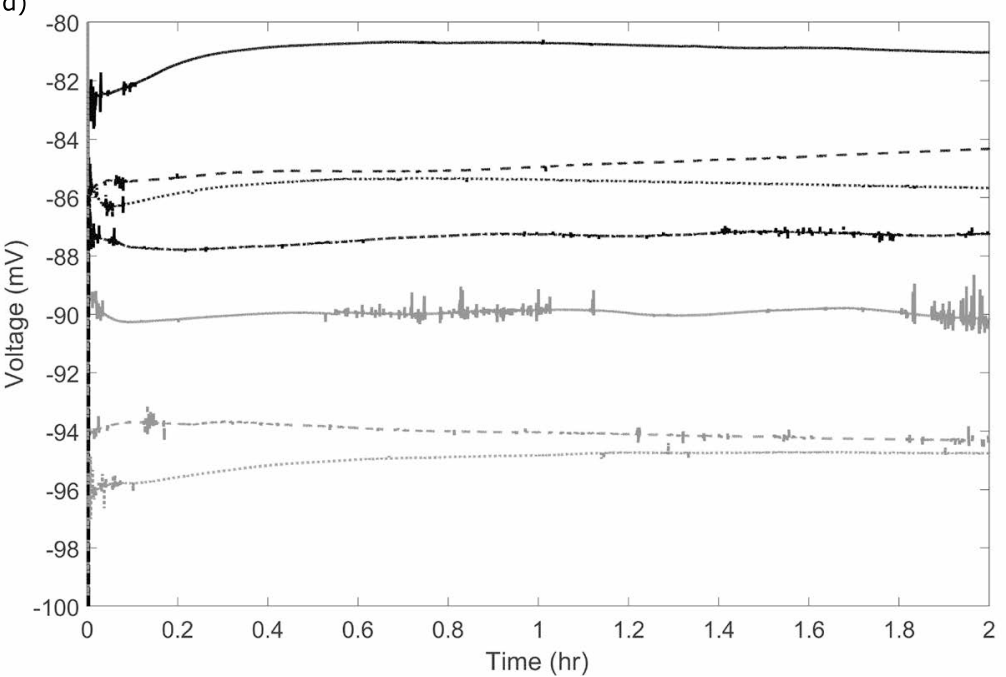

Figure 3. (a) Typical experimental result for the electrochemical exclusion-diffusion "plug" experiment using a chalk sample and groundwater/seawater. The main figure shows the results for the first $2 \mathrm{hr}$ of the experiment, the grey box illustrates the area from which the apparent plug voltage was taken. (b) The results for $5 \mathrm{hr}$ and the area (dashed box) from which the results in (a) are taken, inset (c) shows the results from $10 \mathrm{hr}$ and highlights the area (dashed box) from which the results in (b) are taken. (d) Selected additional results from the plug experiments for chalk illustrating the repeatability and stability of the method, the larger range as compared to the column experiments, reflects the influence of the range of chalk exclusion-diffusion potentials (Table $2 \mathrm{~b}$ ) on the measured voltage.

electrochemical diffusion over exclusion. In contrast, shale and marl samples display negative values of the EED potential, suggesting that electrochemical exclusion is dominant in these lithologies. The pore-throat radius of chalk samples (Table 1), which is typically smaller in the presence of clay minerals (ca. $0.1 \mu \mathrm{m}$ ) than the pore-throat radius of pure chalk (ca. $1 \mu \mathrm{m}$; Fay-Gomord et al., 2016), is clearly an important factor in this regard. Mineral surface charge, which is strongly influenced by the presence of clay (Revil \& Leroy, 2001), also exerts control on exclusion of ions from within the rock pore space (Leinov \& Jackson, 2014). The much smaller pore throat radius in shale and marl samples (Table 1), possibly combined with the higher electrical surface charge represented by the more negative zeta potential in Table 1, results in more significant exclusion of ions from within the pore space of these samples, which in turn results in a more negative EED potential. 


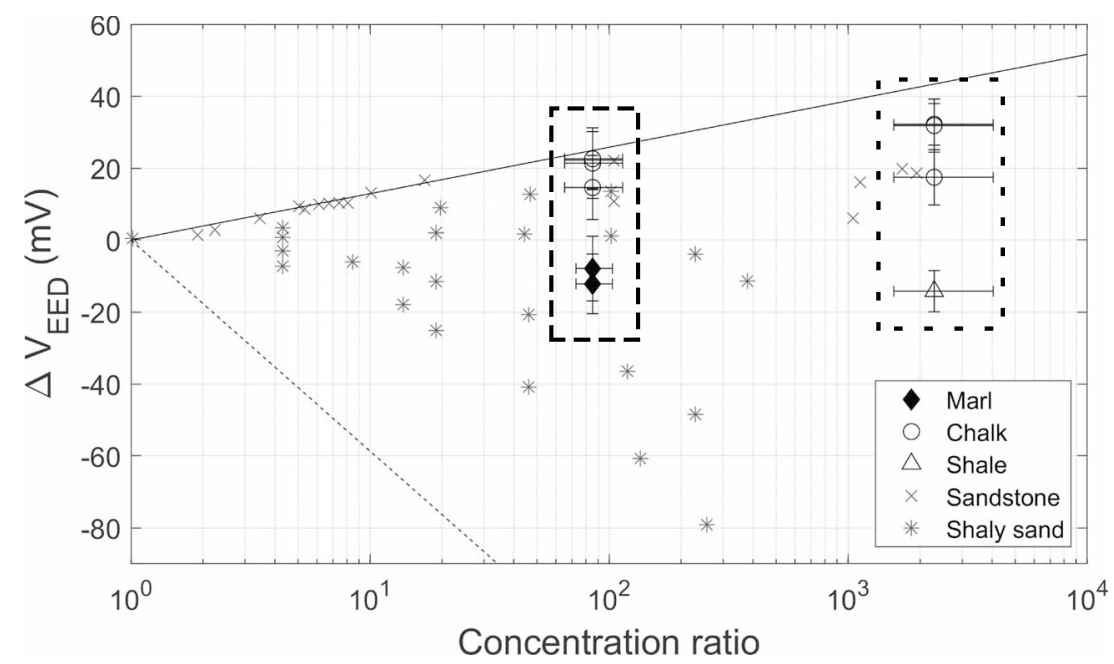

Figure 4. Electrochemical exclusion-diffusion potential in chalk, marl and shale samples. The black line represents the diffusion limit and the dashed line the exclusion limit calculated by Leinov and Jackson (2014). Also shown are values for shaly sand by Hill and Millburn (1956) and sandstone by Leinov and Jackson (2014).

Although Leinov and Jackson (2014) used sandstone samples and the pore throat radius of their samples (ca. $10 \mu \mathrm{m}$ ) was generally an order of magnitude larger than the chalk samples (ca. $1 \mu \mathrm{m}$ ) used in this study (Table 1), the results reported by them (crosses in Figure 4) lie on a similar trend to the chalk results reported here (circles in Figure 4). Leinov and Jackson (2014) used sandstone samples saturated with a $0.1 \mathrm{M} \mathrm{NaCl}$ solution. The saturating solution in the experiments reported here, that is, either natural groundwater $(\sim 0.008 \mathrm{M})$ or preequilibrated chalk DI water $(\sim 0.002 \mathrm{M})$ have an ionic strength ca. 2 orders of magnitude smaller than those used by Leinov and Jackson (2014); thus, more exclusion might be expected in chalk. However, it is possible that since the exclusion of ions also depends on the surface charge (Leinov \& Jackson, 2014), the more positive zeta potential in chalk (Table 1) prevents greater exclusion from occurring, despite its smaller pore throat radii compared to sandstone and the use of similarly low concentrations of saturating electrolyte in each experiment (Vinogradov et al., 2010).

\subsection{The Exclusion Efficiency}

The exclusion efficiency (Westermann-Clark \& Christoforou, 1986) is used to quantify the relative contributions of the exclusion and diffusion potentials to the overall observed EED potential and can be used to upscale the laboratory results to the aquifer or reservoir scales. Using the exclusion efficiency as a parameter in numerical models aids understanding of the effects of geological and geoelectric heterogeneity on electrical signals arising as a result of concentration gradients observed during SP monitoring (Graham et al., 2018). Thus, estimates of the exclusion efficiency are essential for monitoring and prediction of the SP response to the spatial and temporal dynamics of concentration gradients within complex subsurface environments. For example, Graham et al. (2018) relied on field-based estimates of the exclusion efficiency to model the SP response to seawater intrusion in the UK Chalk aquifer. Similarly, the exclusion efficiency is required to understand the contribution of the EED potential during low salinity water flooding in oil and gas reservoirs, migration of contaminant plumes in aquifers and in other subsurface environments were concentration gradients occur. Leinov and Jackson (2014) suggest that the exclusion efficiency $(\eta)$ can be modelled as a linear function of $\frac{r}{\lambda}$, where $r$ is the pore throat radius and $\lambda$ is the Debye length.

The relationship between the pore throat radius $(r)$ and the ionic strength of the saturating electrolyte influences the magnitude and polarity of the EED potential, because this relationship determines the relative influence of the EDL. The size of the diffuse layer within the EDL is dependant on the salinity of the saturating fluid and is thicker at low salinity (Revil \& Pezard, 1999). The characteristic thickness of the diffuse 
layer is given by the Debye length ( $\lambda$; Revil et al., 1999, Leinov \& Jackson, 2014, Jackson, 2015), which is related to the total ionic strength $(I)$ of the electrolyte:

$$
\lambda=\left(\frac{\varepsilon_{w} k_{B} T}{2000 e^{2} N_{A} I}\right)^{\frac{1}{2}}
$$

Here $N_{A}$ is Avogadro's number and $\varepsilon_{w}$ is the electrolyte permittivity. The Debye length (SI Text S4) was calculated for the groundwater saturated core samples $(3.44 \pm 0.14 \mathrm{~nm})$ and the preequilibrated DI water saturated core samples $(6.40 \pm 2.93 \mathrm{~nm})$. The exclusion efficiency was then calculated as follows:

$$
\eta=\frac{\Delta V_{E E D}-\Delta V_{E D}}{\Delta V_{E E}-\Delta V_{E D}}
$$

The limiting value of the diffusion potential $\left(\Delta V_{E D}\right)$ was calculated using equation (3). The limiting value of the exclusion potential $\left(\Delta V_{E E}\right)$ was calculated using (Revil, Cary, et al., 2005):

$$
\Delta V_{E E}=-\frac{k_{B} T}{e} \ln \left(\frac{I_{M i}^{0}}{I_{M i}^{\Delta X}}\right)
$$

were $I_{M i}^{0}$ is the total ionic strength of the high salinity electrolyte and $I_{M i}^{\Delta X}$ is the total ionic strength of the low salinity electrolyte (the ionic strength for each are shown in SI Texts S2 and S3).

In addition to laboratory estimates, equation (9) can also be used to make first-pass estimates of the exclusion efficiency from field measurements of SP and electrical conductivity (Graham et al., 2018). Graham et al. (2018) required estimates of the exclusion efficiency in order to construct models designed to understand the source mechanisms controlling the SP response to seawater intrusion in the UK Chalk aquifer. Here we provide more details of the approach used by Graham et al. (2018) to estimate the exclusion efficiency, validate their estimates using our laboratory measurements, comment on the implications for their fieldbased estimates and broader model results, and discuss potential limitations of the field-based approach to estimating the exclusion efficiency.

In order to make field estimates of the exclusion efficiency, an SP and electrical conductivity log needs to be collected in a borehole which intersects lithologies of interest. Graham et al. (2018) used preexisting data from a borehole in the UK Chalk aquifer (Jones \& Robins, 1999), which had known lithology, to estimate the exclusion efficiency of chalk hardgrounds and marl in the absence of laboratory measurements. Figure 5 shows the SP and electrical conductivity log, used by Graham et al. (2018), to make their estimates of the exclusion efficiency. The borehole from which the logs were taken is in the lithologies of the UK Chalk aquifer as the boreholes from which the chalk samples used in our experiments were obtained. Graham et al. (2018) estimated the exclusion efficiency, by assuming that the borehole is one dimensional and intersects a sharp horizontal saline interface. They also assumed that the SP signal in the borehole is dominated by exclusion-diffusion potential effects (as opposed to electrokinetic or redox potential effects). Comparison of the electrical conductivity and SP logs shown in Figure 5 reveals changes in both parameters across some marl and hardground bands. Assuming that the total change in SP across these horizons provides an estimate of $\Delta V_{E E D}$ and the change in electrical conductivity (which is converted to ionic strength) gives the end members $\Delta V_{E D}$ and $\Delta V_{E E}$, then equation (9) can be used to make an initial estimate of the exclusion efficiency.

Figure 5 shows that distinct, monotonic changes in both SP and electrical conductivity occur adjacent to the Shoreham Marl, the Hope Gap Hardground and the Navigation Marl, as well as between the two Lightpoint Marls. In the case of the Navigation marl, it is not clear whether the changes occur across the chalk or marl horizon, and hence, they have been excluded from further analysis. Similarly, it is not possible to distinguish changes in SP and electrical conductivity across the Lightpoint marls, from changes across the chalk layer that separates them, so these horizons have also been excluded from any further analysis. Applying the salinity and voltage changes, shown by the arrows in Figure 5, to equations (9) and (10) and assuming the variations in SP within the borehole are representative of $\Delta V_{E E D}$ within the adjacent formation gives EED potential estimates for these horizons within the Chalk aquifer (further details in SI Text S6). The field estimates of $\eta$ are shown against $\frac{r}{\lambda}$ in Figure 6, alongside the values derived in the laboratory for chalk, marl, and shale. 


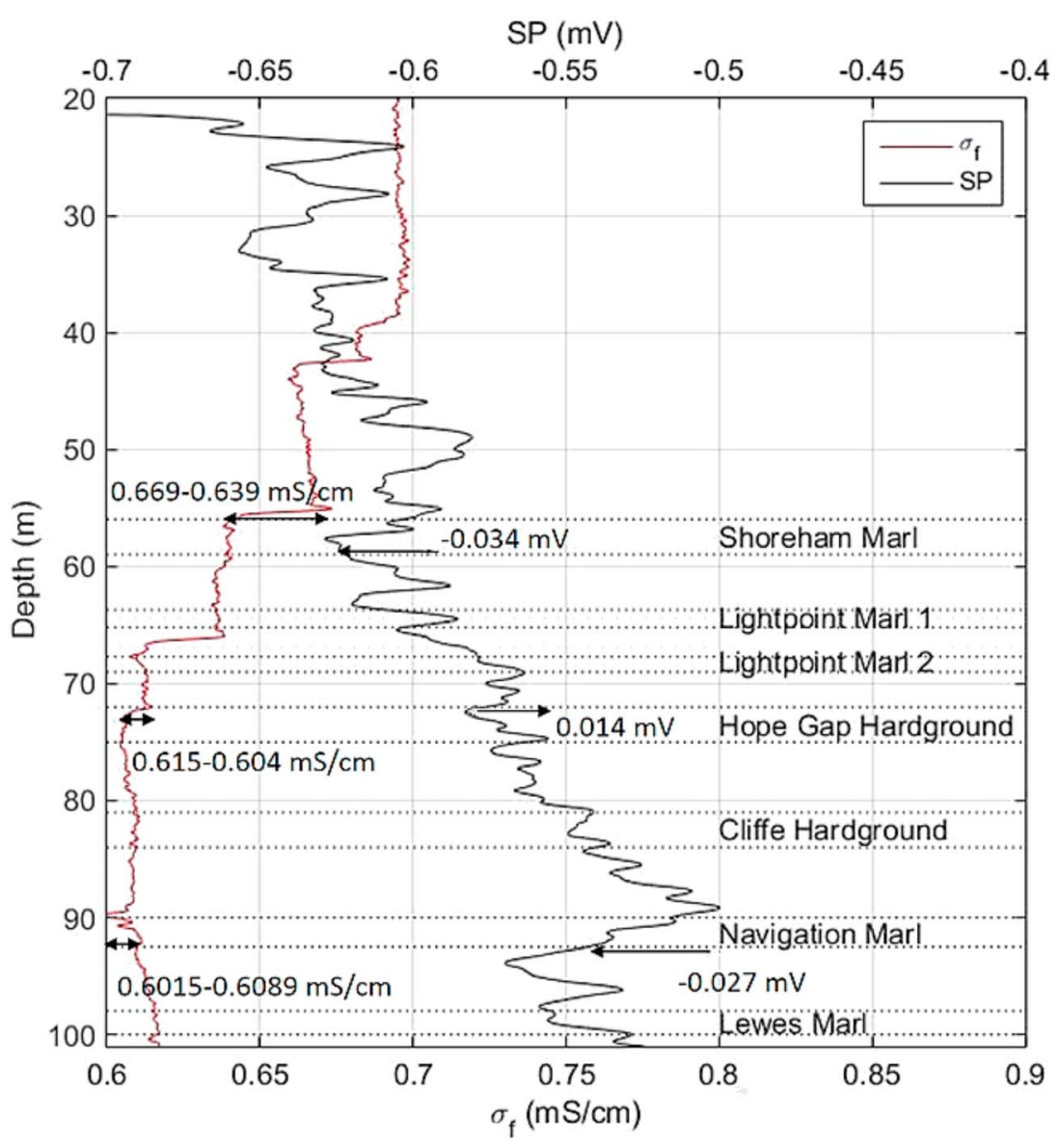

Figure 5. Electrical conductivity and self-potential with depth in the Victoria Gardens Borehole in Brighton, East Sussex, which intersects the same lithologies as the chalk samples used in the experiments. Changes in electrical conductivity and self-potential (sense of change shown by arrow head) across specific hardground and marl horizons are highlighted, based on stratigraphic interpretation by Jones and Robins (1999). This figure is adapted from Graham et al. (2018).

Figure 6 shows that chalk and marl have a comparable exclusion efficiency to sandstones, despite the relatively higher ratio of pore throat radius to Debye length $\left(\frac{r}{\lambda}\right)$ for sandstones (indicated by the position of the black line to the left of our results in Figure 6). Possible hypotheses to explain the similar exclusion efficiency of chalk and marl to sandstones given the difference in $\frac{r}{\lambda}$, are the influence of salinity on the cation exchange capacity and/or the higher surface charge of sandstones (Vinogradov et al., 2010). A higher surface charge in sandstone may explain relatively more exclusion of ions than the surface charge contribution to ion exclusion within chalk. Further work would be required to test these hypotheses.

In general, the simple inverse relationship between exclusion efficiency $(\eta)$ and pore throat diameter $(r)$, proposed by Westermann-Clark and Christoforou (1986), is supported by our measurements in chalk. The highly variable results shown in Figure 6 for marl, hardgrounds, and shale, which have a higher clay content, a smaller pore throat radius and more negative zeta potential (Table 1), suggest that more complex models relating EED potential to surface charge (e.g., Revil \& Jougnot, 2008; Jougnot et al., 2009) should be investigated. However, the required input parameters for these models, such as the mobility of counter-ions at the mineral surface are more difficult to determine (Leinov \& Jackson, 2014).

The similarity between the field and laboratory estimates of the exclusion efficiency of marl supports the model parametrization used by Graham et al. (2018). The parametrization they used was crucial to their finding that geoelectric heterogeneity is the key factor controlling the spatial and temporal behavior and magnitude of SP signals observed in a monitoring borehole ahead of an intruding saline front in the UK Chalk coastal aquifer. The model constructed by Graham et al. (2018) was able to capture the main properties of the SP signals observed in the UK Chalk coastal aquifer, which suggests that the field-based estimates 


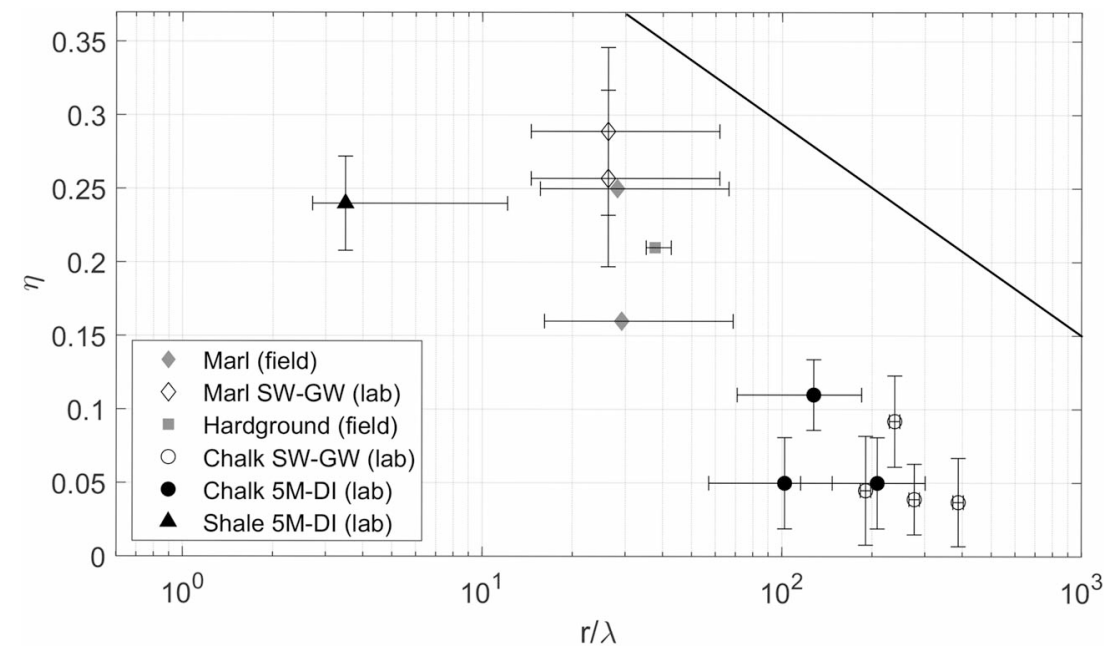

Figure 6. The exclusion efficiency as a function of pore throat radius. The black line shows the empirical relationship derived by Leinov and Jackson (2014), for comparison with their estimates of exclusion efficiency of sandstones. Fieldbased estimates and laboratory estimates are shown. For reasons described in the text it was not possible to calculate errors in the field-based estimates of exclusion efficiency $(\eta)$.

of SP are reliable as an initial rudimentary indicator of the exclusion efficiency. Thus, field estimates could provide useful initial estimates of the exclusion efficiency in heterogeneous subsurface environments where laboratory methods are absent or where it may not be possible to collect core samples. The field estimates also allow a comparison between the likely exclusion efficiency of chalk hardgrounds, which were not tested in the laboratory, and chalk and marl samples for which laboratory measurements were conducted.

Field estimates of exclusion efficiency assume that changes in SP and electrical conductivity with depth in the borehole are representative of $\Delta V_{E E D}$ and $\nabla \ln (C)$ respectively in the adjacent formation. However, the enhanced electrical conductivity of the water column relative to the surrounding formation, as well as mixing within the borehole, is likely to have a dampening effect on these parameters and is a clear source of uncertainty in the field values of exclusion efficiency obtained. It was not possible to quantify the magnitude of this error because the original data came from a secondary source (Jones \& Robins, 1999). In principle, repeated electrical conductivity logging would provide the basis to quantify this error. Unfortunately, during our study, it was not possible to access the original borehole used by Jones and Robins (1999) and to conduct a repeat electrical conductivity log. However, the small discrepancy between the field and laboratory values for marl suggests that borehole data may give a reasonable first-pass estimate of exclusion efficiency in the absence of laboratory measurements. Although hardground samples could not be obtained for laboratory testing, the field-derived hardground values may provide a reasonable estimate of the exclusion efficiency likely to arise across hardground horizons in the Chalk. The laboratory estimates of the exclusion efficiencies are slightly higher than those estimated using the field data. This could be explained by the fact that the rock cores tested in the laboratory comprised 4-5 cm of almost pure marl, in comparison to 1- to 2-m intervals in the boreholes that are likely to comprise an anastomosing mixture of marl and chalk layers. In reality, these larger intervals comprise a mixture of chalk and marl bands and their effective exclusion efficiency values are likely to lie between the values for marl and chalk shown in Figure 6.

\subsection{Implications for Application of SP in Subsurface Environments}

Graham et al. (2018) found that geoelectric heterogeneity is required for the existence of an exclusiondiffusion potential dominated SP precursor (i.e., early warning) prior to the breakthrough of saline water into a coastal monitoring borehole. Here we provide a method for characterizing the type of geoelectric heterogeneity encountered in the Chalk coastal aquifer and similar subsurface environments. Our results confirm that significant geoelectric heterogeneity exists in the Chalk aquifer and demonstrate the importance of rigorous characterization of the exclusion-diffusion potential in subsurface environments where concentration contrasts exist and where SP monitoring is conducted. 
In the absence of suitable core samples or access to specialist laboratories it is possible to obtain initial estimates of the exclusion efficiency from SP and electrical conductivity borehole logs. The results from this technique are consistent with laboratory data from the same lithology. Although this field-based approach may assist in the early stages of model parameterization or provide a useful proof of concept in areas where SP monitoring is being considered, we acknowledge the simplifying assumptions used and recognize that further validation of the method is required to provide confidence, and to quantify uncertainty, in the resulting estimates of exclusion efficiency. Ideally, the laboratory procedures described in this paper should be used to measure the EED potential, estimate the exclusion efficiency, and quantify uncertainty.

The laboratory results provide estimates of the electrical potential that arises in porous media in the presence of concentration gradients, regardless of scale. For a given concentration gradient, the EED potential measured across rock core in the laboratory is the same EED potential, within experimental error, as that found in an aquifer or oil and gas reservoir. Thus, the EED potential measured in the laboratory using the GW/SW concentration gradient is the same electrical potential as that which occurs in a chalk aquifer subject to seawater intrusion. Ultimately, the laboratory measurements provide the most accurate estimates of the exclusion efficiency of aquifer or reservoir material, and these estimates are only limited by the availability of suitable rock core. Ideally, laboratory experiments should be conducted on representative core samples taken from each lithology in the subsurface area under investigation. Like any upscaling procedure, upscaling of the laboratory estimates of EED potential are limited by model assumptions, computational power (i.e., model meshing) and the relationship between core samples and the environment from which samples were taken, that is, how well the samples reflect the heterogeneity of the subsurface. Although upscaling inevitably results in a loss of accuracy, rigorous and thorough laboratory analyses are necessary for improved modelling predictions.

The methods presented here have relevance to any subsurface environment where SP monitoring is conducted and where there is evidence that concentration gradients exist. Therefore, our rigorous and reliable method has broad application to support parameterization of geoelectric models and to understand electrical signals observed during SP monitoring of, amongst other things, enhanced oil and gas recovery (Gulamali et al., 2011; Jackson, Gulamali, et al., 2012), contaminant plume migration in aquifers (Arora et al., 2007; Naudet, 2003; Revil et al., 2009), tracer tests (Ikard et al., 2012; Jougnot et al., 2015), and seawater intrusion (Graham et al., 2018; MacAllister et al., 2018).

\section{Conclusions}

Estimates of the exclusion-diffusion potential component of SP in chalk, marls, and a shale sample were made in order to understand the relative contributions of the exclusion and diffusion potentials to the overall SP likely to be observed in heterogeneous subsurface environments. An existing experimental method was adapted to estimate the EED potential component using natural water and rock samples. The new method successfully produced reliable and repeatable experimental results. The EED potential in chalk is positive and is dominated by the diffusion potential. In the case of marl and a shale, the EED potential is negative and so is dominated by the exclusion component. The smaller pore throat radius in shale and marl is responsible for the negative potential observed and resulted in a higher exclusion efficiency when compared to the chalk samples. First order estimates of the exclusion efficiency can be made using data from borehole SP and electrical conductivity logs, but these are not sufficient to understand the associated uncertainties and should only be used as an indicator of the likely magnitude of the exclusion efficiency. Our results confirm the importance of rigorous characterization of the subsurface prior to conducting SP monitoring and/or geoelectric modelling. The experimental methodology reported here facilitates repeatable characterization of the exclusion-diffusion potential in complex subsurface environments where concentration gradients exist.

\section{References}

Al Mahrouqi, D., Vinogradov, J., \& Jackson, M. D. (2017). Zeta potential of artificial and natural calcite in aqueous solution. Advances in Colloid and Interface Science, 240, 60-76. https://doi.org/10.1016/j.cis.2016.12.006

Alroudhan, A., Vinogradov, J. \& Jackson, M. Zeta potential in carbonates at reservoir conditions-application to ior. Ior 2015-18th European Symposium on Improved Oil Recovery, 2015.

Alroudhan, A., Vinogradov, J., \& Jackson, M. D. (2016). Zeta potential of intact natural limestone: impact of potential-determining ions Ca, Mg and SO4. Colloids and Surfaces A: Physicochemical and Engineering Aspects, 493, 83-98. https://doi.org/10.1016/j.colsurfa.2015.11.068 
Arora, T., Linde, N., Revil, A., \& Castermant, J. (2007). Non-intrusive characterization of the redox potential of landfill leachate plumes from self-potential data. Journal of Hydrology, 92(3-4), 274-292. https://doi.org/10.1016/j.jconhyd.2007.01.018

Barati, P., Shahbazi, K., Kamari, M., \& Aghajafari, A. (2017). Shale hydration inhibition characteristics and mechanism of a new aminebased additive in water-based drilling fluids. Petroleum, 3(4), 476-482. https://doi.org/10.1016/j.petlm.2017.05.003

Barry, P. H., \& Diamond, J. M. (1970). Junction potentials, electrode standard potentials, and other problems in interpreting electrical properties of membranes. The Journal of Membrane Biology, 3(1), 93-122. https://doi.org/10.1007/BF01868010

Bloomfield, J. P., Brewerton, L. J., \& Allen, D. J. (1995). Regional trends in matrix porosity and dry density of the Chalk of England. Quarterly Journal of Engineering Geology and Hydrogeology, 28(Supplement 2), S131-S142.

Byrne, M. \& Patey, I. Core sample preparation-An insight into new procedures. International Symposium of The Society of Core Analysts, Abu Dhabi, UAE, 2004

Darnet, M., Maineult, A., \& Marquis, G. (2004). On the origins of self-potential (SP) anomalies induced by water injections into geothermal reservoirs. Geophysical Research Letters, 31, L19609. https://doi.org/10.1029/2004GL020922

Eith, C., Kolb, M., Seubert, A., \& Viehweger, K. H. (2001). Practical ion chromatography. Herisau, Switzerland: Metrohm Ltd.

Fay-Gomord, O., Soete, J., Katika, K., Galaup, S., Caline, B., Descamps, F., et al. (2016). New insight into the microtexture of chalks from NMR analysis. Marine and Petroleum Geology, 75, 252-271. https://doi.org/10.1016/j.marpetgeo.2016.04.019

Franson, M. A. (1998). Standard methods for the examination of water and wastewater, (20th ed.). Washington: Dc, American Public Health Association, Standard Methods Committee.

Graham, M., Macallister, D., Vinogradov, J., Jackson, M., \& Butler, A. (2018). Self-potential as a predictor of seawater intrusion in coastal groundwater boreholes. Water Resources Research, 54, 6055-6071. https://doi.org/10.1029/2018WR022972

Gulamali, M. Y., Leinov, E., \& Jackson, M. D. (2011). Self-potential anomalies induced by water injection into hydrocarbon reservoirs Geophysics, 76(4), F283-F292. https://doi.org/10.1190/1.3596010

Haynes, W. M., \& Lide, D. R. (2012). CRC handbook of chemistry and physics: A ready-reference book of chemical and physical data: $2012-$ 2013, Boca Raton (Fla.). London; New York: CRC Press.

Hill, H. J., \& Millburn, J. D. (1956). Effect of clay and water salinity on electrochemical behavior of reservoir rocks. Petroleum Transactions, Aime, 207, 65-72.

Hounslow, A. (1995). Water quality data: Analysis and interpretation. CRC Press.

Ikard, S. J., Revil, A., Jardani, A., Woodruff, W. F., Parekh, M., \& Mooney, M. (2012). Saline pulse test monitoring with the self-potential method to nonintrusively determine the velocity of the pore water in leaking areas of Earth dams and embankments. Water Resources Research, 48, W04201. https://doi.org/10.1029/2010wr010247

Jackson, M. D. (2015). 11.09 - Tools and techniques: Self-potential methods. In G. Schubert (Ed.), Treatise on Geophysics (2nd ed., Chap. 11.09). Oxford: Elsevier. https://doi.org/10.1016/B978-0-444-53802-4.00208-6

Jackson, M. D., Al-Mahrouqi, D., \& Vinogradov, J. (2016). Zeta potential in oil-water-carbonate systems and its impact on oil recovery during controlled salinity water-flooding. Scientific Reports, 6(1), 37363. https://doi.org/10.1038/srep37363

Jackson, M. D., Butler, A. P., \& Vinogradov, J. (2012). Measurements of spontaneous potential in chalk with application to aquifer characterisation in the southern UK. Quarterly Journal of Engineering Geology and Hydrogeology, 45(4), 457-471. https://doi.org/10.1144/ qjegh2011-021

Jackson, M. D., Gulamali, M. Y., Leinov, E., Saunders, J. H., \& Vinogradov, J. (2012). Spontaneous potentials in hydrocarbon reservoirs during waterflooding: application to water-front monitoring. SPE Journal, 17(01), 53-69. https://doi.org/10.2118/135146-PA

Jackson, P. E. (2000). Ion chromatography in environmental analysis. Encyclopedia of Analytical Chemistry. John Wiley \& Sons, Ltd. https:// doi.org/10.1002/9780470027318.a0835

Jardani, A., Dupont, J. P., \& Revil, A. (2006). Self-potential signals associated with preferential groundwater flow pathways in sinkholes. Journal of Geophysical Research, 111, B09204. https://doi.org/10.1029/2005JB004231

Jardani, A., Revil, A., Boleve, A., \& Dupont, J. P. (2008). Three-dimensional inversion of self-potential data used to constrain the pattern of groundwater flow in geothermal fields. Journal of Geophysical Research, 113, B09204. https://doi.org/10.1029/2007JB005302

Jones, H. K. \& Robins, N. S. (Eds.) 1999. The chalk aquifer of the south downs: British Geological Survey.

Jougnot, D., \& Linde, N. (2013). Self-potentials in partially saturated media: The importance of explicit modeling of electrode effects. Vadose Zone Journal, 12.

Jougnot, D., Linde, N., Haarder, E. B., \& Looms, M. C. (2015). Monitoring of saline tracer movement with vertically distributed selfpotential measurements at the HOBE agricultural test site, Voulund, Denmark. Journal of Hydrology, 521, 314-327. https://doi.org/ 10.1016/j.jhydrol.2014.11.041

Jougnot, D., Revil, A., \& Leroy, P. (2009). Diffusion of ionic tracers in the Callovo-Oxfordian clay-rock using the Donnan equilibrium model and the formation factor. Geochimica et Cosmochimica Acta, 73(10), 2712-2726. https://doi.org/10.1016/j.gca.2009.01.035

Junge, A. (1990). A new telluric $\mathrm{KCl}$ probe using Filloux's AgAgCl electrode. In W. H. Campbell (Ed.), Deep Earth Electrical Conductivity, Pure and Applied Geophysics (pp. 589-598). Birkhäuser Basel. https://doi.org/10.1007/978-3-0348-7435-9_8

Kulessa, B. (2003). Cross-coupled flow modeling of coincident streaming and electrochemical potentials and application to subglacial selfpotential data. Journal of Geophysical Research, 108(B8), 2381. https://doi.org/10.1029/2001JB001167

Lanteri, Y., Szymczyk, A., \& Fievet, P. (2009). Membrane potential in multi-ionic mixtures. Journal of Physical Chemistry B, 113(27), 9197-9204. https://doi.org/10.1021/jp901110c

Leinov, E., \& Jackson, M. D. (2014). Experimental measurements of the SP response to concentration and temperature gradients in sandstones with application to subsurface geophysical monitoring. Journal of Geophysical Research: Solid Earth, 119, 6855-6876. https:// doi.org/10.1002/2014JB011249

Leinov, E., Vinogradov, J., \& Jackson, M. D. (2010). Salinity dependence of the thermoelectric coupling coefficient in brine-saturated sandstones. Geophysical Research Letters, 37, L23308. https://doi.org/10.1029/2010gl045379

MacAllister, D. J., Jackson, M. D., Butler, A. P., \& Vinogradov, J. (2016). Tidal influence on self-potential measurements. Journal of Geophysical Research: Solid Earth, 121, 8432-8452. https://doi.org/10.1002/2016JB013376

MacAllister, D. J., Jackson, M. D., Butler, A. P., \& Vinogradov, J. (2018). Remote detection of saline intrusion in a coastal aquifer using borehole measurements of self-potential. Water Resources Research, 54, 1669-1687. https://doi.org/10.1002/2017WR021034

Maineult, A., Strobach, E., \& Renner, J. (2008). Self-potential signals induced by periodic pumping tests. Journal of Geophysical Research, 113, B01203. https://doi.org/10.1029/2007JB005193

Mammar, N., Rosanne, M., Prunet-Foch, B., Thovert, J. F., Tevissen, E., \& Adler, P. M. (2001). Transport properties of compact clays: I. Conductivity and permeability. Journal of Colloid and Interface Science, 240(2), 498-508. https://doi.org/10.1006/jcis.2001.7697 
Naudet, V. (2003). Relationship between self-potential (SP) signals and redox conditions in contaminated groundwater. Geophysical Research Letters, 30(21), 2091. https://doi.org/10.1029/2003GL018096

Nelson, P. H. (2009). Pore-throat sizes in sandstones, tight sandstones, and shales. AAPG Bulletin, 93(3), 329-340. https://doi.org/10.1306/ 10240808059

Nourbehecht, B. 1963. Irreversible thermodynamic effects in inhomogeneous media and their application in certain geoelectric problems $\mathrm{PhD}, \mathrm{MIT}$.

Ortiz Jr., I., Von Goten, J. R. \& Osoba, J. S. 1973. Relationship of the electrochemical potential of porous media with hydrocarbon saturation. The Log Analyst, 25-32.

Raynauld, J.-P., \& Laviolette, J. R. (1987). The silver-silver chloride electrode: A possible generator of offset voltages and currents. Journal of Neuroscience Methods, 19(3), 249-255. https://doi.org/10.1016/S0165-0270(87)80009-2

Revil, A. (1999). Ionic diffusivity electrical conductivity membrane and thermoelectric potentials in colloids and granular porous media: A unified model. Journal of Colloid and Interface Science, 212(2), 503-522. https://doi.org/10.1006/jcis.1998.6077

Revil, A., Cary, L., Fan, Q., Finizola, A., \& Trolard, F. (2005). Self-potential signals associated with preferential ground water flow pathways in a buried paleo-channel. Geophysical Research Letters, 32, L07401. https://doi.org/10.1029/2004GL022124

Revil, A., \& Jougnot, D. (2008). Diffusion of ions in unsaturated porous materials. Journal of Colloid and Interface Science, 319(1), 226-235.

Revil, A., \& Leroy, P. (2001). Hydroelectric coupling in a clayey material. Geophysical Research Letters, 28(8), 1643-1646. https://doi.org/ $10.1029 / 2000 G L 012268$

Revil, A., Leroy, P., \& Titov, K. (2005). Characterization of transport properties of argillaceous sediments: Application to the CallovoOxfordian argillite. Journal of Geophysical Research, 110, B06202. https://doi.org/10.1029/2004JB003442

Revil, A., \& Pezard, P. A. (1999). Streaming potential in porous media 1. Theory of the zeta potential. Journal of Geophysical Research, 104(B9), 20,021-20,031. https://doi.org/10.1029/1999JB900089

Revil, A., Schwaeger, H., Cathles, L. M. III, \& Manhardt, P. D. (1999). Streaming potential in porous media 2. Theory and application to geothermal systems. Journal of Geophysical Research, 104(B9), 20,033-20,048. https://doi.org/10.1029/1999JB900090

Revil, A., Trolard, F., Bourrie, G., Castermant, J., Jardani, A., \& Mendonca, C. A. (2009). Ionic contribution to the self-potential signals associated with a redox front. Journal of Contaminant Hydrology, 109(1-4), 27-39. https://doi.org/10.1016/j.jconhyd.2009.07.008

Rizzo, E., Suski, B., \& Revil, A. (2004). Self-potential signals associated with pumping tests experiments. Journal of Geophysical Research, 109, B10203. https://doi.org/10.1029/2004jb003049

Smits, L. J. M. (1968). SP log interpretation in shaly sands. Society of Petroleum Engineers Journal, 243, 123-136.

Snyder, K. V., Kriegstein, A. M., \& Sachs, F. (1999). A convenient electrode holder for glass pipettes to stabilize electrode potentials. Pflügers Archiv, 438(3), 405-411. https://doi.org/10.1007/s004240050928

Tallgren, P., Vanhatalo, S., Kaila, K., \& Voipio, J. (2005). Evaluation of commercially available electrodes and gels for recording of slow EEG potentials. Clinical Neurophysiology, 116(4), 799-806. https://doi.org/10.1016/j.clinph.2004.10.001

Tatro, M. E., \& Amarasiriwardena, D. (2006). Optical emission inductively coupled plasma in environmental analysis, Encyclopedia of Analytical Chemistry. John Wiley \& Sons, Ltd. https://doi.org/10.1002/9780470027318.a0848

Thomas, E. C. (1976). Determining Qv from membrane potential measurements on shaly sands. Journal of Petroleum Technology, 28, 1086-1096

Vieira, C., Maineult, A., \& Zamora, M. (2012). Laboratory study of self-potential signals during releasing of $\mathrm{CO}_{2}$ And N-2 plumes. Comptes Rendus Geoscience, 344(10), 498-507. https://doi.org/10.1016/j.crte.2012.09.002

Vinogradov, J., Jaafar, M. Z., \& Jackson, M. D. (2010). Measurement of streaming potential coupling coefficient in sandstones saturated with natural and artificial brines at high salinity. Journal of Geophysical Research, 115, B12204. https://doi.org/10.1029/2010jb007593

Westermann-Clark, G. B., \& Christoforou, C. C. (1986). The exclusion diffusion potential in charged porous membranes. Journal of Electroanalytical Chemistry, 198(2), 213-231. https://doi.org/10.1016/0022-0728(86)90001-X 